\title{
Lesões gástricas em equinos de abatedouro: avaliação macroscópica e histológica
}

\author{
Gastric lesions in horses from slaughterhouse: macroscopic and histologic evaluation
}

\author{
Maria Verônica de Souza ${ }^{{ }^{*}}$ Marcela Bueno Martins da Costa ${ }^{\mathrm{I}}$ \\ José de Oliveira Pinto ${ }^{I}$ João Carlos Pereira da SilvaI José Dantas Ribeiro Filho \\ José do Carmo Lopes Moreira ${ }^{\mathrm{I}}$
}

RESUMO

\begin{abstract}
O objetivo deste estudo foi avaliar a frequência de lesões nas diferentes regiões do estômago de equinos assintomáticos. Foi realizada avaliação macroscópica dos estômagos, onde foi verificada a natureza da lesão. Na sequência, foram obtidos fragmentos de cinco regiões previamente mapeadas para exame histológico, assim como de outras áreas com lesões. De um total de 21 animais, apenas um apresentou lesão macroscópica isolada na região glandular, seis na região aglandular, 13 em ambas as regiões, enquanto um animal não apresentava lesões. Histologicamente, as alterações mais frequentes foram gastrite (19/21), úlceras (14/21) e erosão (8/21). A maioria dos casos foi de úlcera e erosão agudas, e de gastrite crônica. Os resultados do presente estudo revelam a elevada frequência de lesões no estômago de equinos aparentemente sadios, oriundos de abatedouro.
\end{abstract}

Palavras-chave: cavalos, gastrite, erosão, úlcera, microscopia.

\section{ABSTRACT}

The aim of this study was to evaluate the frequency of lesions in different regions of stomach of asymptomatic horses. Stomachs were evaluated macroscopically, which identified the nature of lesions. Subsequently, fragments were obtained from five regions previously mapped for histological examination, as well as from other areas with lesions. From a total of 21 animals, only one had isolated macroscopic lesion in glandular region, six in nonglandular region and 13 showed lesions in both regions. One animal showed no macroscopic lesion. Histologically, the most frequent lesions were gastritis (19/21), ulcers (14/21) and erosion (8/21). Most cases were acute ulcer and erosion, and gastritis chronic. The results of this study show the high frequency of lesions in the stomach of apparently healthy slaughter horses.

Key words: equine, gastritis, erosion, ulcer, microscopy.

\section{INTRODUÇÃO}

Alterações gástricas em equinos podem ser assintomáticas, ou resultar apenas em sinais clínicos inespecíficos, como diminuição do apetite, bruxismo, mudanças de comportamento, perda da condição corpórea, cólica aguda ou recorrente e diarreia crônica (ANDREWS et al., 2005), sendo geralmente diagnosticadas por endoscopia. Existe inadequada correlação entre severidade da lesão e a sintomatologia clínica (le JEUNE et al., 2009), de forma que animais com lesões profundas podem apresentar apenas discreto quadro de cólica, enquanto outros apresentam intenso desconforto abdominal na presença de lesões superficiais.

Vários fatores de risco podem estar associados às lesões gástricas do equino, como alterações no tipo de dieta (excessiva quantidade de concentrado, baixa ingestão de feno), estresse (aplicação de medicamentos, transporte, hospitalização, privação de alimento e água), jejum prolongado e exercício (tipo, intensidade e frequência de treinamento). A administração de drogas inflamatórias não-esteroidais (AINEs) é um fator predisponente importante, devido à frequência de utilização desses fármacos. Além disso, estudo destaca a Helicobacter como possível causa de úlcera gástrica (MORALES et al., 2010), uma vez que a infecção por essa bactéria é uma frequente causa de úlcera em outras espécies. Por outro lado, a Helicobacter spp pode estar presente na mucosa

IDepartamento de Veterinária, Universidade Federal de Viçosa (UFV), 36570-000, Viçosa, MG, Brasil. E-mail: msouza@ufv.br.

*Autor para correspondência. 
gástrica sem qualquer evidência de associação com lesões (HUSTED et al., 2010).

Úlceras e erosões podem ser encontradas tanto na região glandular como aglandular (le JEUNE et al., 2009), havendo controvérsias entre os pesquisadores no que se refere à região mais acometida. Conhecer mais profundamente a respeito das lesões gástricas dos equinos é fundamental não apenas com respeito aos aspectos clínicos e do bem estar animal, mas também é uma necessidade, já que o estômago é um órgão incluído nos cortes resfriados e congelados para exportação. O objetivo deste estudo foi determinar e mapear lesões no estômago de equinos assintomáticos, oriundos de abatedouro.

\section{MATERIAL E MÉTODOS}

Foram incluídos no estudo equinos mestiços, aparentemente sadios, oriundos de abatedouro no Estado de Minas Gerais. Todos os animais foram submetidos a exame físico, sendo avaliadas as variáveis frequência cardíaca, frequência respiratória, tempo de enchimento capilar, temperatura corporal, grau de hidratação, movimentos intestinais e coloração das mucosas. Imediatamente após o abate, o estômago foi removido, sendo então realizada uma incisão ao longo da sua curvatura maior. O órgão foi suavemente lavado com água corrente e submetido a uma minuciosa avaliação macroscópica, onde foi verificada a natureza da lesão. Úlceras e erosões foram classificadas, conforme mencionado por LEITE et al. (2012), de acordo com o sistema de graduação proposto pelo conselho da síndrome da úlcera gástrica equina (SUGE), sendo 0: epitélio intacto; 1: mucosa com áreas hiperêmicas e/ou hiperceratose (espessamento do epitélio aglandular); 2: presença de erosões pequenas, isoladas ou multifocais, ou presença de úlceras; 3: presença de úlceras grandes, isoladas ou multifocais, ou extensa erosão e sangramento; e 4: extensas úlceras, com profunda penetração da submucosa.

Na sequência, foram obtidos fragmentos de aproximadamente $2 \mathrm{~cm}^{2}$ de cinco diferentes regiões pré-estabelecidas, sendo dois oriundos da região aglandular e três da região glandular (cárdica, fúndica e pilórica): 2cm distal ao esfíncter do cárdia (zona 1); $2 \mathrm{~cm}$ proximal ao margo plicatus (zona 2); $2 \mathrm{~cm}$ distal ao margo plicatus, na região cárdica glandular, ao longo da curvatura maior (zona 3); região fúndica glandular, ao longo da curvatura maior (zona 4) e $6 \mathrm{~cm}$ distal ao margo plicatus, na região pilórica (zona 5). Amostras também foram obtidas de outras áreas que apresentassem lesões macroscópicas. Os fragmentos foram colocados em formol neutro a $10 \%$, processados rotineiramente, e corados pela hematoxilina-eosina (HE). Foram examinados por três avaliadores, sem prévio conhecimento sobre a macroscopia gástrica. A natureza das lesões, o tipo celular predominante, densidade e localização do infiltrado inflamatório foram avaliados em seis diferentes campos. Diagnóstico de gastrite foi baseado no sistema de graduação de Sydney. Foi utilizado o seguinte escore para o infiltrado celular; 0: ausente; 1 : discreto (1 a 50 células); 2: moderado (51 a 150 células); e 3: intenso (acima de 150 células). Para a distribuição das lesões, também foi considerado um escore numérico de 0 a 3, sendo: 0: ausente; 1: focal; 2: regional; e 3: difusa, o que correspondeu com o número de lesões macroscópicas definidas por MACALLISTER et al. (1997). Os achados foram analisados de forma descritiva, utilizando porcentagem.

\section{RESULTADOS E DISCUSSÃO}

Foram incluídos no presente estudo 21 animais, sendo 15 machos castrados e seis fêmeas. A idade variou entre 3 e 28 anos $(15,95 \pm 5,86)$. O exame físico revelou variáveis físicas dentro dos limites de referência para a espécie. Uma porcentagem muito elevada $(95,23 \%)$ dos animais abatidos possuía alguma lesão gástrica. Apenas um (4,76\%) equino não mostrou alteração macroscópica. Um deles $(4,76 \%)$ apresentou lesão unicamente na região glandular e seis $(28,57 \%)$ na aglandular. Os demais (61,91\%) apresentaram pelo menos uma lesão em ambas as regiões. Na aglandular, o grau 2 de lesão foi o mais frequente $(8 / 21)$ (erosões pequenas, isoladas ou multifocais, ou presença de úlceras), seguido pelo grau 4 (6/21) (extensas úlceras, com profunda penetração da submucosa). Já na região glandular, foi o grau 1 (11/21) (mucosa com áreas hiperêmicas e/ou com hiperceratose). Portanto, macroscopicamente, a região aglandular foi mais frequentemente afetada por erosões ou úlceras. Esse grau de lesão também foi encontrado por LEITE et al. (2012), em exame post mortem de equinos sem quadro clínico de comprometimento do estômago. O maior envolvimento da região aglandular se deve à constante exposição ao ácido clorídrico ( $\mathrm{HCl})$, pepsina e ácidos biliares, por estar recoberta por epitélio estratificado escamoso, que não possui capacidade protetora de tamponamento, como ocorre com a mucosa glandular que contém a camada muco-bicarbonato (ANDREWS et al., 1999). A região glandular também possui um adequado fluxo sanguíneo, capacidade de restituição celular, secreção de prostaglandinas e fatores de 
crescimento (ANDREWS et al., 2005). Por essa razão, a maioria dos pesquisadores considera mais raras as lesões erosivas e/ou ulcerativas na mucosa glandular, conforme observado nos animais do presente estudo. Entre as possíveis causas de lesões na região glandular, são mencionadas a utilização de AINEs, o refluxo retrógrado de conteúdo duodenal, a presença de bactérias Helicobacter e o estresse. O estresse aumenta o cortisol endógeno (FURR et al., 1992), o que resulta na inibição da síntese de prostaglandinas, que é fundamental para a proteção da mucosa (ANDREWS et al., 2005), uma vez que o fluxo sanguíneo e a secreção de muco são dependentes desse eicosanoide.

O exame macroscópico revelou 16/21 (76,2\%) estômagos com úlceras com diferentes formatos e dimensões (Figura 1a). Em 15/16 $(93,75 \%)$ as úlceras estavam presentes apenas na região aglandular, e em 1/16 (6,25\%) em ambas as regiões. Segundo ANDREWS et al. (1999), a úlcera gástrica é definida como uma alteração da mucosa, na qual ocorre destruição dos elementos celulares, resultando em um defeito que pode se estender até a lâmina própria. Lesões menos severas, consideradas como superficiais, são denominadas de erosão e frequentemente são precursores de úlceras clínicas. No presente estudo, essas lesões superficiais foram observadas em 9/21 (42,85\%) estômagos, e apresentavam formatos circulares ou de estrias, de coloração rósea ou amarelada, associada ou não a outras alterações, afetando a região aglandular (7/9) ou glandular (2/9). Algumas delas estavam acompanhadas por hemorragia, sendo definidas como erosão (Figura 1b).

O exame histológico dos estômagos com macroscopia de úlcera revelou em 14/16(87,5\%) perda total do epitélio, se estendendo até a lâmina própria, com infiltrado inflamatório predominantemente neutrofílico (Figura 1c). Já nos casos das erosões presentes na região aglandular ficou demonstrado que, em 4/7 (57,14\%) estômagos, havia perda total do epitélio de revestimento e infiltrado inflamatório do tipo neutrofílico, acompanhado ou não de congestão vascular, caracterizando um quadro de úlcera, e não de erosão como indicado na macroscopia. Achado histológico compatível com erosão foi constatado apenas em 3/7 (42,85\%) estômagos, caracterizada pela perda parcial do epitélio e infiltrado inflamatório misto. Os estômagos com macroscopia de erosão na região glandular apresentavam discreto infiltrado de linfócitos e congestão vascular, caracterizando um quadro de gastrite crônica ativa (Figura 2a).
A exceção de dois animais, todos os demais com macroscopia de hiperemia na região glandular (escore 1) apresentaram quadro de gastrite na microscopia. A gastrite é a inflamação da mucosa gástrica com infiltrado celular, acompanhado ou não de alterações no epitélio. De acordo com CARPENTER \& TALLEY (1995), o processo pode ser agudo ou crônico, e somente o exame histológico fornece um diagnóstico preciso, de forma que o termo

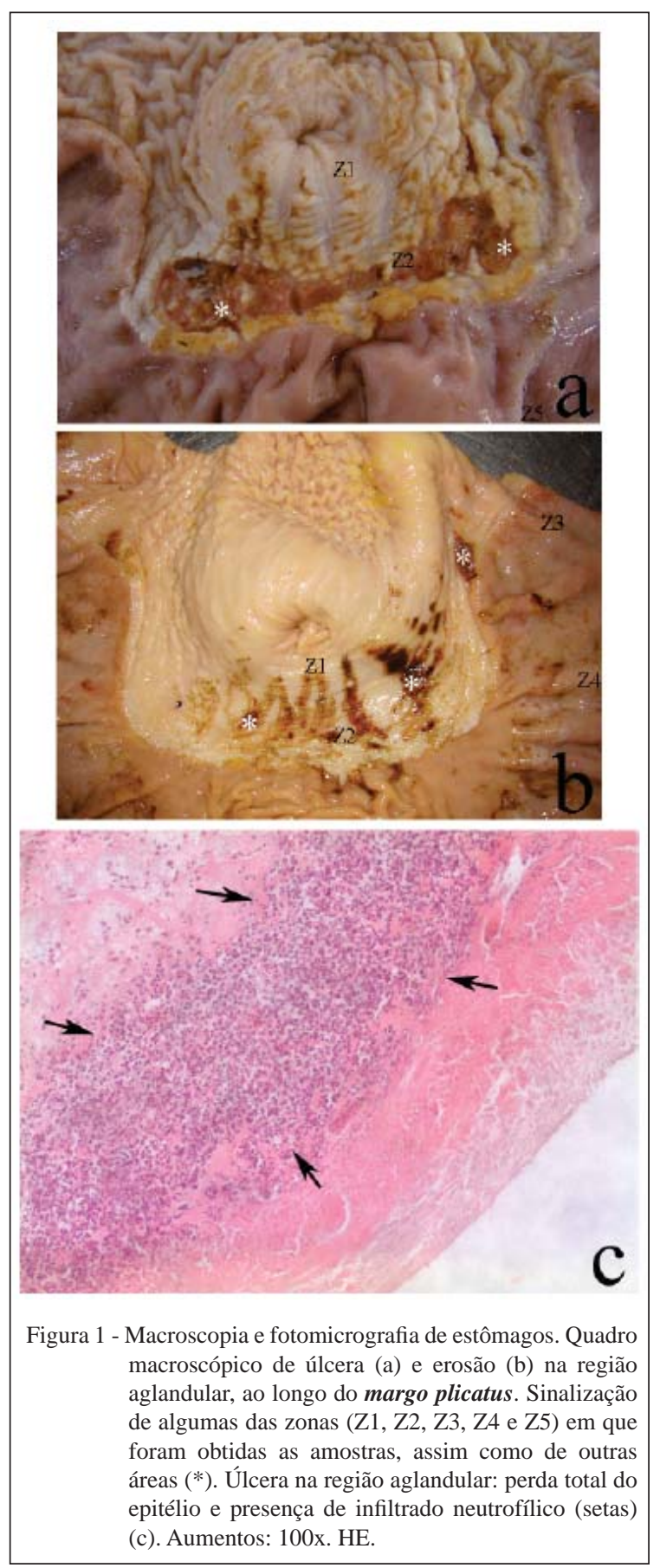




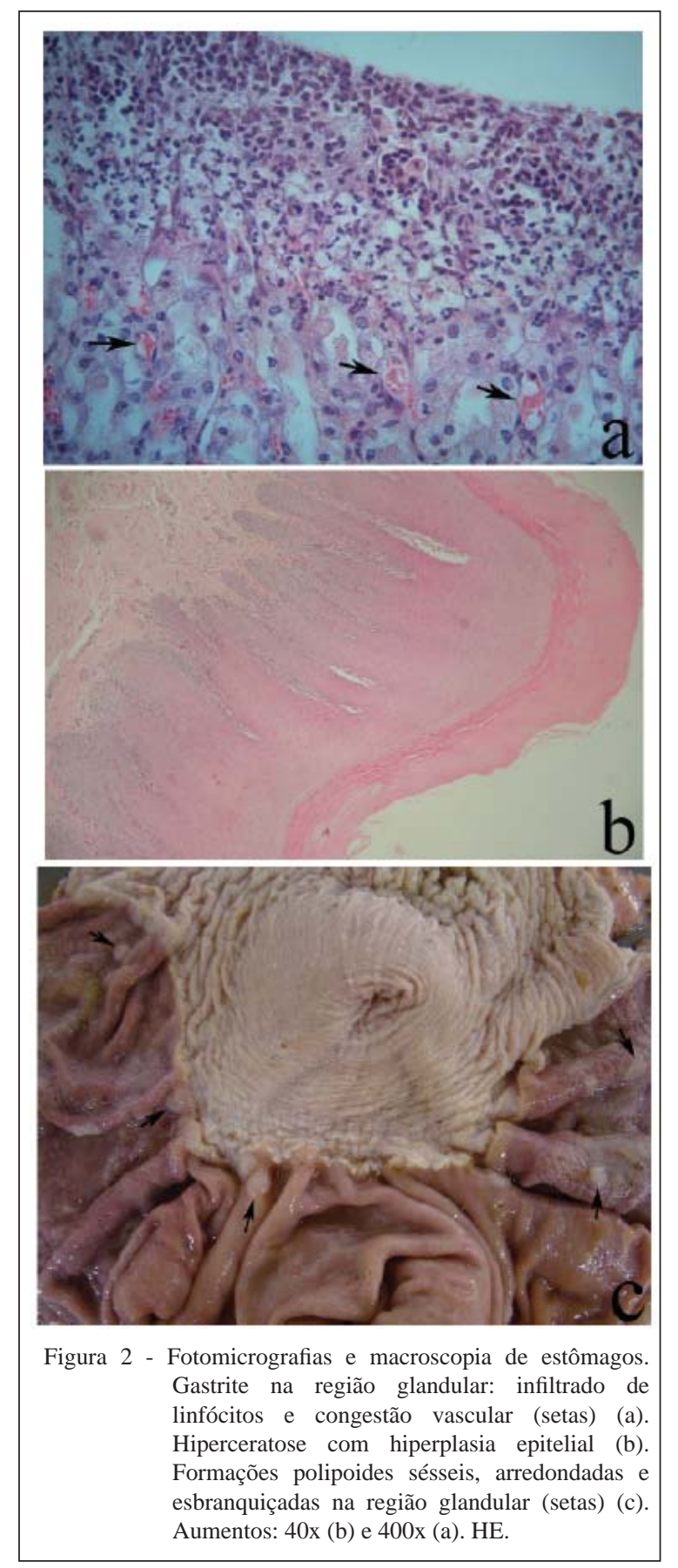

gastrite não deve ser usado indiscriminadamente para descrever alterações sem evidências histológicas de inflamação. A tabela 1 apresenta a descrição histológica do estômago de cada animal, e caracteriza a presença de gastrite baseada no sistema de graduação de Sydney. Em 17/20 (85\%) animais, as lesões macroscópicas estavam localizadas próximas ou ao longo do margo plicatus, o que corrobora os resultados de LEITE et al. (2012), que avaliaram o estômago de 14 animais Puro Sangue Inglês durante exame post mortem. Esse achado era esperado, uma vez que, conforme mencionado previamente, a região aglandular é desprovida de proteção e está constantemente exposta ao $\mathrm{HCl}$, pepsina e ácidos biliares que irritam a mucosa. Além disso, o margo plicatus possui menor aporte sanguíneo por ter um padrão microvascular. De acordo com STASZYK et al. (2001), a redução no fluxo sanguíneo, que pode inclusive estar associada ao estresse, pode ocasionar uma maior predisposição a lesões.

As úlceras e erosões observadas na região aglandular, na presença de alterações circulatórias, apresentavam infiltrado de neutrófilos, sendo, portanto, consideradas como agudas. Já na região glandular essas lesões foram crônicas, já que estavam desprovidas de alterações vasculares e acompanhadas por infiltrados mononucleares.

Gastrite foi uma lesão muito frequente na região glandular, estando presente em 19/21 (90,47\%) animais, sendo crônica em 18/19 estômagos. Um total de 16/19 (84,21\%) equinos apresentou gastrite regional. Gastrite focal foi observada no epitélio da região glandular dos animais de número 13, 14 e 19. Elevada frequência desse processo inflamatório em equinos adultos submetidos a jejum hídrico (6 h) e alimentar (24 h) foi mencionada por FERNANDES et al. (2003). Segundo os autores, a inflamação da mucosa é um achado comum em animais aparentemente sadios. Por outro lado, os autores não realizaram avaliação microscópica para comprovação das lesões. A relação pH e alteração gástrica já é bastante conhecida. De acordo com MURRAY \& SCHUSSER (1993), o pH do conteúdo gástrico de animais alimentados de forma contínua permanecerá ao redor de 3,1, entretanto o jejum prolongado pode resultar em valores tão baixos como 1,6.

Um estômago que apresentou úlceras e erosões tanto na macroscopia como na microscopia da região aglandular também possuía glândulas císticas dilatadas na amostra obtida próxima ao cárdia, com luz ampla e revestida por epitélio mais achatado. O achado histológico foi compatível com ninho de glândulas ectópicas na submucosa, também denominado de metaplasia glandular. O mesmo caso foi relatado em dois equinos por MARTINEAU et al. (2009), na submucosa dos locais com erosões profundas. De acordo com HUSTED et al. (2008), esse achado pode ser decorrente de um desenvolvimento progressivo natural de proteção que ocorre ao longo da vida do equino, devido à continua 
Tabela 1 - Diagnóstico histológico do estômago dos 21 equinos.

\begin{tabular}{|c|c|c|}
\hline Animais & Região aglandular & Região glandular \\
\hline 1 & Úlcera aguda & Gastrite crônica discreta (F) ou intensa (C). \\
\hline 2 & Úlcera e erosão agudas. & Gastrite crônica discreta (C). \\
\hline 3 & Úlcera e erosão agudas. & Gastrite crônica discreta (C e P) ou intensa (F). \\
\hline 4 & Úlcera aguda. & Gastrite crônica discreta (C) ou moderada (F). \\
\hline 5 & Ulcera aguda. & Gastrite crônica discreta (C e F) ativa. \\
\hline 6 & --- & Gastrite crônica discreta (C e F) ativa. \\
\hline 7 & Úlcera aguda. & Gastrite crônica discreta (F e P). \\
\hline 8 & Úlcera aguda. & --- \\
\hline 9 & Úlcera aguda. & Gastrite crônica discreta (F) e intensa (P). \\
\hline 10 & Úlcera aguda e metaplasia gl. & Gastrite crônica discreta (C e P) e intensa (F). \\
\hline 11 & --- & Gastrite aguda discreta (F). Erosão crônica.** \\
\hline 12 & Úlcera aguda. & Erosão crônica. \\
\hline 13 & --- & Gastrite crônica discreta (C). Erosão crônica. \\
\hline 14 & Hiperceratose. & Gastrite crônica discreta (C) e moderada (P). \\
\hline 15 & Úlcera aguda. & Gastrite crônica discreta (F) ativa. \\
\hline 16 & Úlcera aguda e Hiperceratose. & Gastrite crônica intensa (P). \\
\hline 17 & Erosão aguda ativa. Hiperceratose. & Gastrite crônica discreta (F) e moderada (C e P). \\
\hline 18 & Úlcera e erosão agudas. & Gastrite crônica moderada (P). \\
\hline 19 & --- & Gastrite crônica discreta (P). \\
\hline 20 & Erosão aguda. & Gastrite crônica discreta (C) e moderada (F). \\
\hline 21 & Úlcera aguda. Hiperceratose. & Gastrite crônica intensa (P). \\
\hline
\end{tabular}

F: fúndica, C: cardica, P: pilórica. gl: glandular, **: Pólipo pediculado.

exposição do epitélio escamoso a conteúdos gástricos. Hiperceratose foi observada em 4/21 estômagos (Tabela 1), e se caracterizou macroscopicamente por regiões com discreto espessamento da mucosa. A microscopia revelou aumento da espessura da camada córnea, acompanhada de hiperplasia epitelial (Figura 2b). Para MARTINEAU et al. (2009), essa alteração se deve à reação do epitélio escamoso à exposição excessiva ao ácido clorídrico.

Múltiplas formações polipoides sésseis, arredondadas e esbranquiçadas (Figura 2c), de aproximadamente $1 \mathrm{~cm}$ de diâmetro, com algumas delas apresentando superfície enegrecida, foram observadas na região glandular de 4/21 (19,04\%) estômagos. Avaliação microscópica revelou se tratar de hiperplasia glandular, separada por abundante estroma, dilatação cística e alteração na arquitetura das células. De acordo com AGUIRRE \& IGLESIAS (2000), nos seres humanos essas lesões são raras e geralmente não acarretam manifestações clínicas, sendo achados acidentais em 50 a $60 \%$ dos casos, e podem estar associadas à presença de $\boldsymbol{H}$. pylori e gastrite auto-imune. Nos equinos, essas lesões podem estar associadas aos nematoides T. axei e
D. megastoma, assim como com a larva de mosca Gasterophillus spp (van der KOLK \& VELDHUIS KROEZE, 2013). Outro estômago (1/21) apresentou formação pediculada, de consistência fibroelástica e coloração rósea próxima ao margo plicatus, com aproximadamente $1,2 \mathrm{~cm}$ de diâmetro. Histologicamente, a lesão estava constituída por glândulas tubulares mucosecretoras, situadas em estroma conjuntivo na presença de células inflamatórias, com vasos de paredes espessadas. Algumas glândulas apresentaram dilatação cística. Achado macroscópico semelhante já foi relatado (HUSTED et al., 2010).

Em 6/21 (28,57\%) estômagos que não apresentavam importante lesão macroscópica na região glandular, graduados como 0 pela classificação proposta pelo conselho da SUGE, foram observados infiltrados inflamatórios mononucleares (5/6), caracterizando um quadro de gastrite (discreta a intensa), perda parcial do epitélio nas regiões cárdica e pilórica (1/6), associada à gastrite crônica. Adicionalmente, o animal sem alteração macroscópica apresentou gastrite discreta, caracterizada por infiltrado de linfócitos (mucosa da região pilórica). 
Na maioria dos animais que apresentaram úlcera na região aglandular, com lesão em grau 1 ou sem alteração macroscópica na região glandular, havia microscopia de gastrite crônica (discreta a intensa) ou erosão. Não foi realizada comparação entre severidade das lesões e achados histológicos, já que, no exame macroscópico, pode ocorrer interpretação errônea da gravidade ou do tipo de lesão, conforme observado no estudo realizado por MARTINEAU et al. (2009). Segundo ANDREWS et al. (2002), é necessário precaução ao se interpretar achados macroscópicos por endoscopia, sendo fundamental a realização de técnicas mais precisas de avaliação para confirmação dos achados. Nesse contexto, a biópsia deve ser parte integrante do exame endoscópico para diagnóstico de lesões gástricas em equinos. Por outro lado, a técnica é especialmente valiosa para amostragens realizadas a partir da região glandular. Estudo realizado por RODRIGUES et al. (2009) revelou que fragmentos obtidos da mucosa aglandular costumam ser menores em comparação com aqueles originados da glandular. Nesse sentido, normalmente não possuem toda a mucosa e a área superficial da lâmina própria, mas apenas o epitélio escamoso estratificado, sendo, portanto, a biópsia por endoscopia inadequada para diagnóstico histológico dessa região.

Na presente pesquisa, as áreas lesionadas macroscopicamente apresentaram maior frequência de alterações histológicas em cinco animais (23,81\%), em comparação com as zonas de coleta pré-determinadas. Por outro lado, mostraram-se menos comprometidas em quatro equinos (19,05\%). Entretanto, na maioria dos casos (n=8, 38,09\%), não foi diferente das demais localidades avaliadas. Em quatro (19,05\%) animais, não foram obtidas amostras de tecidos além das cinco zonas. Esses resultados sugerem que as áreas de coletas utilizadas no exame post mortem foram satisfatórias em revelar alterações microscópicas.

A combinação dos métodos adotados no presente estudo, buscando avaliar as lesões gástricas em equinos assintomáticos, permitiu um melhor entendimento das alterações, o que é fundamental para a definição do tratamento e prognóstico. Apesar da elevada ocorrência de lesões nos estômagos de animais provenientes de abatedouro, os achados observados no presente estudo não impediriam o consumo da carne dos animais afetados, uma vez que essas afecções são consideradas como uma manifestação localizada, sem comprometimento da carcaça ou de outro órgão. O procedimento usual empregado nesses casos é apenas rejeição parcial, com condenação do órgão afetado.

\section{CONCLUSÃO}

Os resultados obtidos no presente estudo permitem concluir que equinos aparentemente sadios apresentam elevada frequência de úlceras ou erosões na região aglandular e de gastrite crônica na região glandular do estômago.

\section{COMITÊ DE ÉTICA E BIOSSEGURANÇA} no Uso Animal.

Essa pesquisa foi aprovada pela Comissão de Ética

\section{AGRADECIMENTOS}

Os autores agradecem à Fundação de Amparo à Pesquisa do estado de Minas Gerais (FAPEMIG), à Coordenação de Aperfeiçoamento de Pessoal de Nível Superior (CAPES) e ao Conselho Nacional de Desenvolvimento Científico e Tecnológico (CNPq) pelo suporte financeiro.

\section{REFERÊNCIAS}

AGUIRRE, P.A.; IGLESIAS, J.L.V. Pólipos gástricos. Revista de Gastroenterologia, v.20, n.4, p.213-222, 2000. Disponível em: <http://www.cirugest.com/htm/revisiones/cir13-05/13-05-01. pdf>. Acesso em: 20 maio, 2013.

ANDREWS, F.M. et al. Gastric ulcers in horses. Journal of Animal Science, Suppl.83, p.8-21, 2005. Disponível em: <http:// www.journalofanimalscience.org/content/83/13_suppl/E18.full. pdf>. Acesso em: 7 nov. 2013.

ANDREWS, F.M. et al. Recommendations for the diagnosis and treatment of equine gastric ulcer syndrome (EGUS). Equine Veterinary Education, v.1, n.2, p.122-134, 1999. Disponível em: $<$ http://onlinelibrary.wiley.com/doi/10.1111/j.2042-3292.1999. tb00961.x.>. Acesso em: 13 de nov. 2012. doi: 10.1111/j.20423292.1999.tb00961.x.

ANDREWS, F.M. et al. Comparison of endoscopic, necropsy and histology scoring of equine gastric ulcers. Equine Veterinary Journal, v.34, n.5, p.475-478, 2002. Disponível em: <http://www. ncbi.nlm.nih.gov/pubmed/12358050>. Acesso em: 7 nov. 2013. doi: $10.2746 / 042516402776117827$.

CARPENTER, H.A.; TALLEY, NJ. Gastroscopy is incomplete without biopsy: clinical relevance of distinguishing gastropathy from gastritis. Gastroenterology, v.108, n.3, p.917-24, 1995. Disponível em: <http://www.ncbi.nlm.nih.gov/pubmed/7875496>. Acesso em: 7 nov. 2013. doi: 10.1016/0016-5085(95)90468-9.

FERNANDES, W.R. et al. Achados gastroscópicos em eqüinos adultos assintomáticos. Arquivo Brasileiro de Medicina Veterinária e Zootecnia, v.55, n.4, p.405410, 2003. Disponível em: <http://www.scielo.br/scielo. php?script=sci_arttext\&pid=S0102-09352003000400004\&nrm =iso\&tlng=pt $>$. Acesso em: 7 nov. 2013. doi: 10.1590/S010209352003000400004.

FURR, M.O. et al. The effects of stress on gastric ulceration, T3, $\mathrm{TH}$, reverse T3 and cortisol in neonatal foals. Equine Veterinary Journal, v.24, n.1, p.37-40, 1992. Disponível em: <http://www. 
ncbi.nlm.nih.gov/pubmed/1555538>. Acesso em: 7 nov. 2013. doi: 10.1111/j.2042-3306.1992.tb02776.x.

HUSTED, L. et al. Effect of paddock vs. stall housing on 24 hour gastric $\mathrm{pH}$ within the proximal and ventral equine stomach. Equine Veterinary Journal, v.40, n.4, p.337-341, 2008. Disponível em: $<$ http://onlinelibrary.wiley.com/doi/10.2746/042516408X284673/ pdf $>$. Acesso em: 7 nov. 2013. doi: 10.2746/042516408X284673.

HUSTED, L. et al. Examination of equine glandular stomach lesions for bacteria, including Helicobacter spp by fluorescence in situ hybridization. BMC Microbiology, v.10, n.84, p.1471-2180, 2010. Disponível em: <http://www.biomedcentral.com/1471-2180/10/84> Acesso em: 7 nov. 2013. doi: 10.1186/1471-2180-10-84.

LEITE J.S. et al. Gastroduodenal lesions in racehorses: evaluation and mapping according to the updated Sidney system and equine gastric ulcer Council classification. Brazilian Journal of Veterinary Pathology, v.5, n.2, p.51-59, 2012. Disponível em: <http:// www.abpv.vet.br/upload/documentos/DOWNLOAD-FULLARTICLE-13-20881_2012_8_18_19_8.pdf>. Acesso em: 7 nov. 2013.

le JEUNE, S.S. et al. Prevalence of gastric ulcers in Thoroughbred broodmares in pasture: a preliminary report. Equine Veterinary Journal, v.181, n.3, p.251-255, 2009. Disponível em: <http:// www.sciencedirect.com/science/article/pii/S1090023308001330>. Acesso em: 7 nov. 2013. doi: 10.1016/j.tvjl.2008.03.020.

MACALLISTER, C.G. et al. A scoring system for gastric ulcers in the horse. Equine Veterinary Journal, v.29, n.6, p.430433, 1997. Disponível em: <http://onlinelibrary.wiley.com/ doi/10.1111/j.2042-3306.1997.tb03154.x/pdf>. Acesso em: 7 nov. 2013. doi: 10.1111/j.2042-3306.1997.tb03154.x.

MARTINEAU, $\mathrm{H}$. et al. Pathology of gastritis and gastric ulceration in the horse. Part 1: range of lesions present in 21 mature individuals. Equine Veterinary Journal, v.41, n.7, p.638-644, 2009. Disponível em: <http://www.ncbi.nlm. nih.gov/pubmed/19927581>. Acesso em: 7 nov. 2013. doi: 10.2746/042516409X464816.

MORALES, B.A. et al. Detection of Helicobacter -like organisms in Thoroughbred horses from Venezuela. Brazilian Journal of Veterinary Pathology, v.3, n.1, p.52-55, 2010. Disponível em: <http://www.abpv.vet.br/upload/documentos/V. 3,-N.1,-10-20881_2010_4_29_37_24.pdf>. Acesso em: 7 nov. 2013.

MURRAY, M.J.; SCHUSSER, G.F. Measurement of 24-h gastric $\mathrm{pH}$ using an indwelling pelectrode in horses unfed, fed and treated with ranitidine. Equine Veterinary Journal, v.25, n.5, p.417-421, 1993. Disponível em: <http://www.ncbi.nlm.nih.gov/ pubmed/8223373>. Acesso em: 7 nov. 2013. doi: 10.1111/j.20423306.1993.tb02983.x.

RODRIGUES, N.L.F. et al. Validation of a transendoscopic glandular and nonglandular gastric biopsy technique in horses. Equine Veterinary Journal, v.41, n.7, p.631-635, 2009. Disponível em: <http://www.ncbi.nlm.nih.gov/pubmed/19927580>. Acesso em: 11 jan. 2014. doi: 10.2746/042516409X424144.

STASZYK, C. et al. Mucosal microvasculature of the gastric pars nonglandularis and margo plicatus in the horse: a scanning electron microscopic study on corrosion casts. Annals of Anatomy, v.183, n.3, p.255-259, 2001. Disponível em: <http://www.ncbi.nlm.nih. gov/pubmed/11396796>. Acesso em: 7 nov. 2013. doi: 0.1016/ S0940-9602(01)80228-4.

van der KOLK, J.H.; VELDHUIS KROEZE, E.J.B. Ectoparasitical diseases. In: __ . Infectious diseases of the horse. Diagnosis, pathology, management, and public health. London : Manson Publishing, 2013. Cap.5, p.208-216. 